\title{
On-Chip Stretching, Sorting, and Electro-Optical Nanopore Sensing of Ultra-Long Human Genomic DNA
}

\author{
Adam Zrehen ${ }^{1}$, Diana Huttner ${ }^{1}$ and Amit Meller ${ }^{1,2, \#}$
}

1. Department of Biomedical Engineering, Technion -IIT, Haifa, Israel, 32000

2. Russell Berrie Nanotechnology Institute, Technion -IIT, Haifa, Israel, 32000

\# Corresponding author. Email: ameller@technion.ac.il

\section{Supplementary Information}

\section{Table of Contents}

1. Device fabrication overview

2. Images of collapsed membranes

3. DNA combing of nick-translated DNA

4. Additional laser drilling traces

5. Device noise characterization

6. Genomic DNA extraction protocol

7. Summary of tested devices

8. Pillar hooking and unhooking examples

9. Polymer extension estimation

10. Translocation speed calculation

11. Nanopore collisions 


\section{Device fabrication overview}

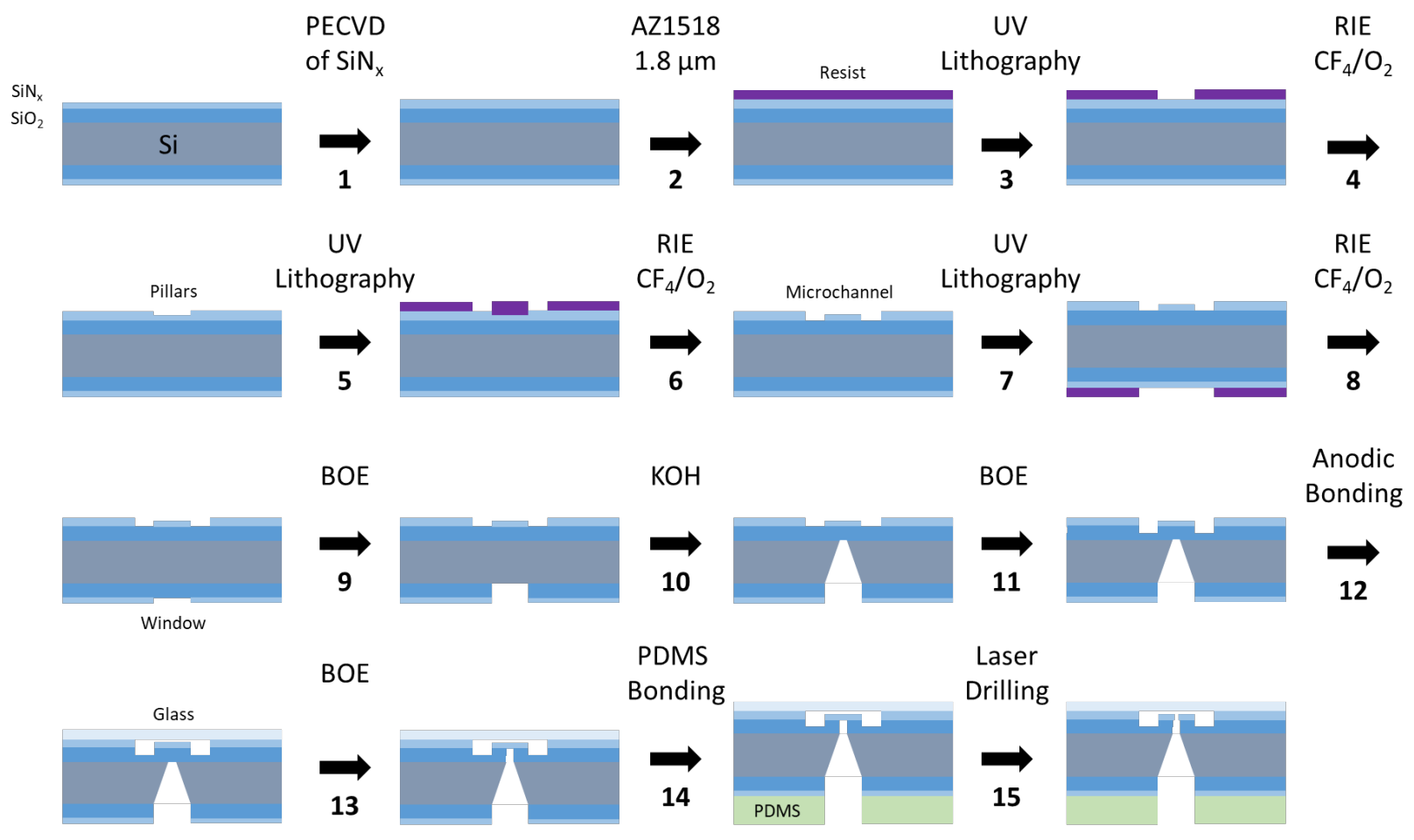

Figure S1. Device fabrication. (1) A starting 4-inch $\mathrm{Si} / \mathrm{SiO}_{2} / \mathrm{SiN}_{\mathrm{x}}(350 \mu \mathrm{m} / 500 \mathrm{~nm} / 50 \mathrm{~nm})$ wafer was coated with $200 \mathrm{~nm}$ of low-stress $\mathrm{SiN}_{\mathrm{x}}$ by plasma-enhanced chemical vapor deposition $\left(300^{\circ} \mathrm{C}\right)$ to increase the channel depth formed in subsequent steps. (2) AZ1518 resist was spin-coated to a thickness of $1.8 \mu \mathrm{m}$ and pillar structures were exposed by UV light and then (3) developed in Novo Developer. (4) The pattern was subsequently etched $200 \mathrm{~nm}$ deep into the $\mathrm{SiN}_{\mathrm{x}}$ by reactive ion etching (RIE) using 1:1 $\mathrm{CF}_{4}: \mathrm{O}_{2}$. (5) Microchannels were frontside aligned to the pillars by UV lithography and (6) subsequently etched through the full $250 \mathrm{~nm}$ thickness of the $\operatorname{SiN}_{\mathrm{x}}$. (7) Windows to be opened into free-standing membranes and through-ports were backside aligned to the pillar structures and (8) etched by RIE. (9) The underlying $\mathrm{SiO}_{2}$ was then etched by buffered oxide etch (BOE). (10) $<100>$ silicon was anisotropically etched by $33 \% \mathrm{KOH}$ overnight. (11) The microchannels were deepened to $600-700 \mathrm{~nm}$ by BOE prior to (12) anodic bonding to glass. (13) The $\mathrm{SiO}_{2}$ layer supporting the free-standing membrane was removed by BOE. (14) The chip and a PDMS slab were plasma-activated, aligned and permanently bonded on a $120^{\circ} \mathrm{C}$ hotplate for 10 mins. (15) Lastly, nanopores were fabricated in individual chips by laser-etching. 


\section{Images of collapsed membranes}

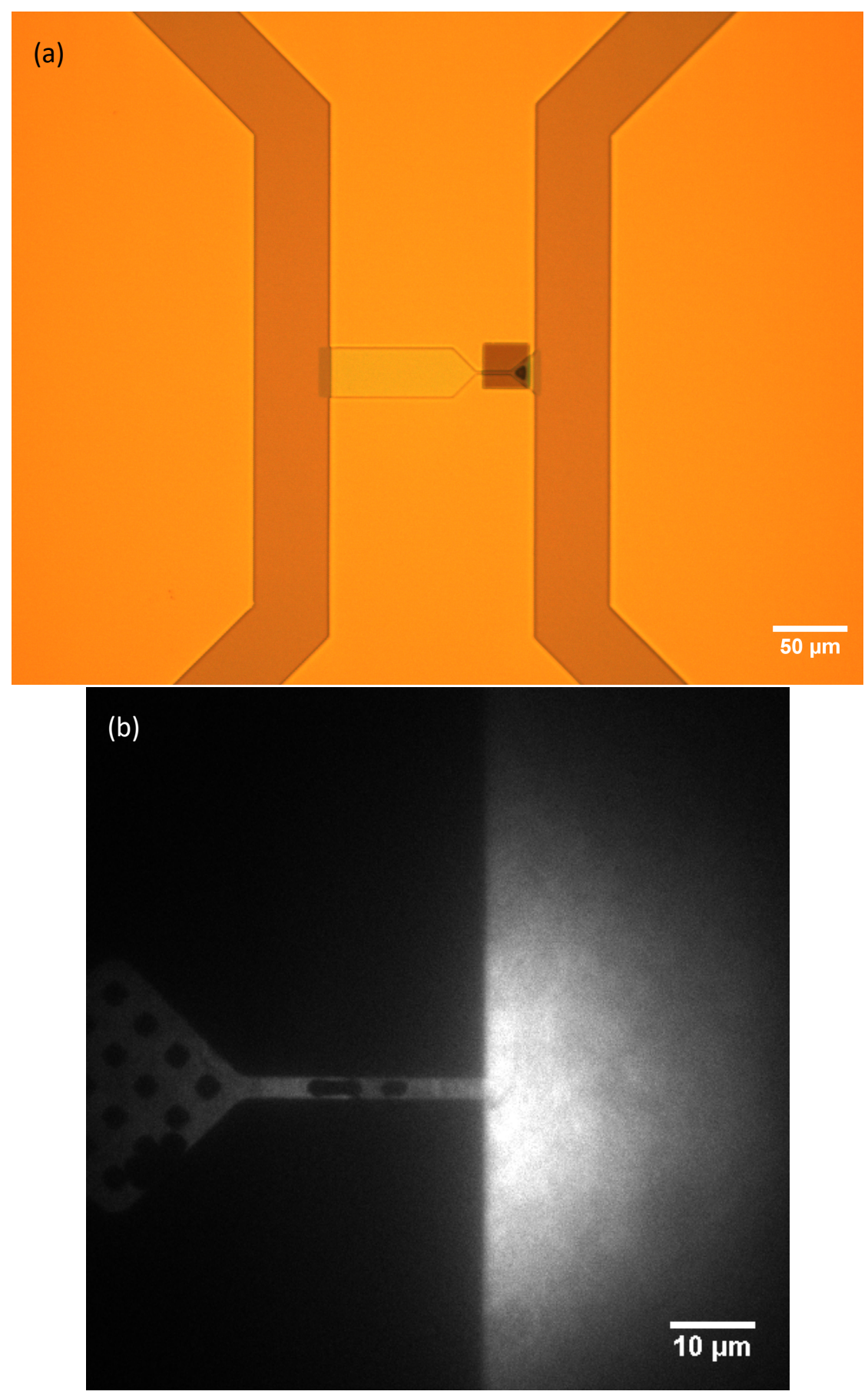

Figure S2-Collapsed freestanding membrane post-anodic bonding. (a) Altenative preliminary design without pillars and an expanding channel exit showing membrane collapse at higher aspect rations despite being supported by an underyling $500 \mathrm{~nm} \mathrm{SiO}{ }_{2}$ layer. (b) $100 x$ image of channel flushed with Alexa Fluor 488 dye, revealing contrasted area where membrane collapse occurred due to inadequate $\mathrm{SiO}_{2}$ support. 


\section{DNA combing of nick-translated DNA}

DNA molecules at a concentration of 0.1-1 $\mathrm{ng} / \mu \mathrm{l}$ were stained with YOYO-1 fluorescent dye at a ratio of 20-25:1 (base pairs: dye) in TE buffer (10 mM Tris-HCl, $1 \mathrm{mM}$ EDTA), and DTT (100 mM), and diluted $1 / 10$ in TE buffer before stretching on glass activated by N-trimethoxysilylpropyl-N,N,Ntrimethylammonium chloride and vinyltrimethoxysilane as described by Sidorava et al. ${ }^{1}$

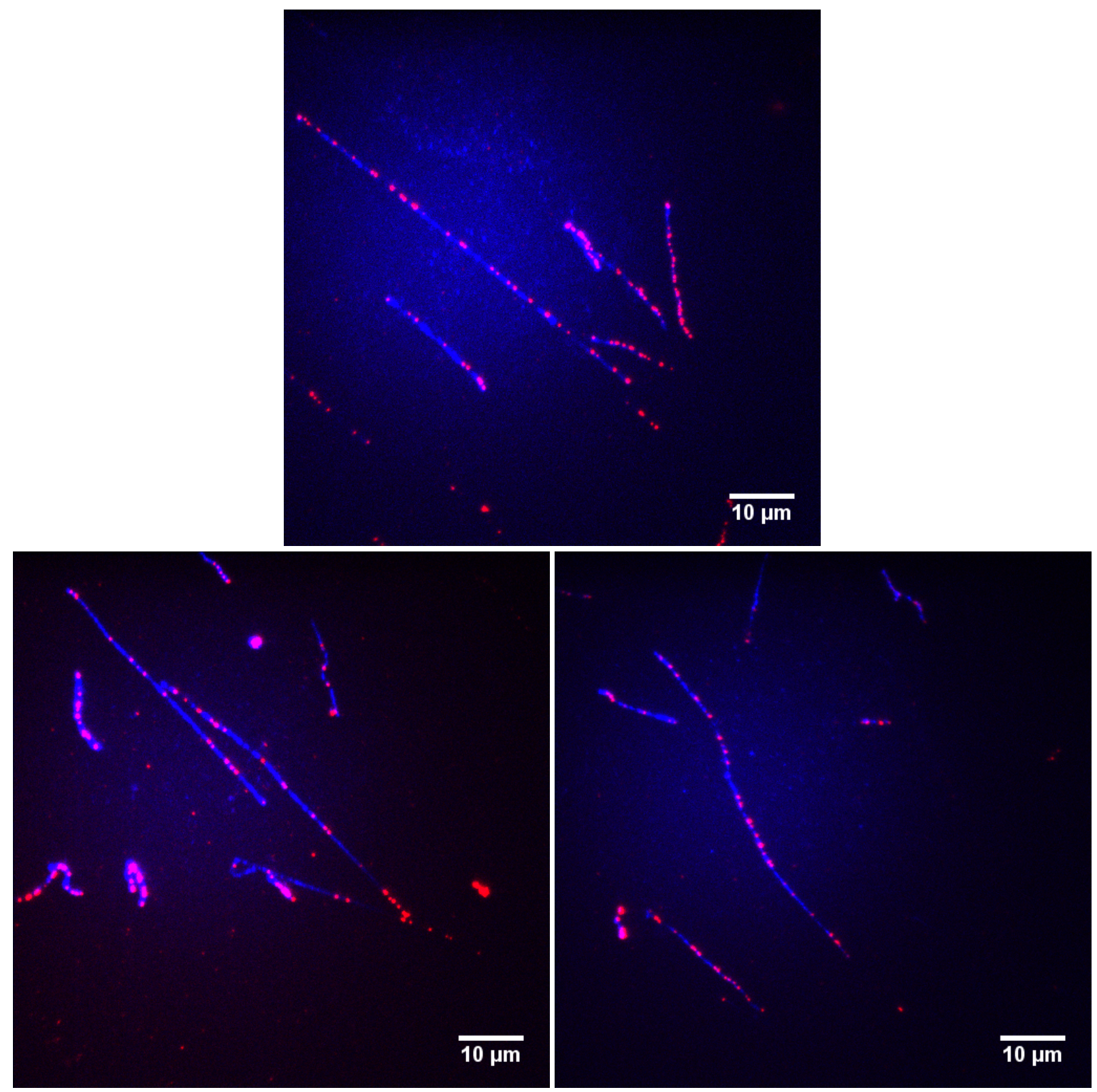

Figure S3. Nick-translated genomic DNA stretched on glass. Genomic DNA extracted from human colon cancer cells were labelled with dUTP-Atto647N (red) by nick-translation with Nt.BspQI and subsequently labelled by YOYO-1 (blue). 


\section{Additional laser drilling traces}
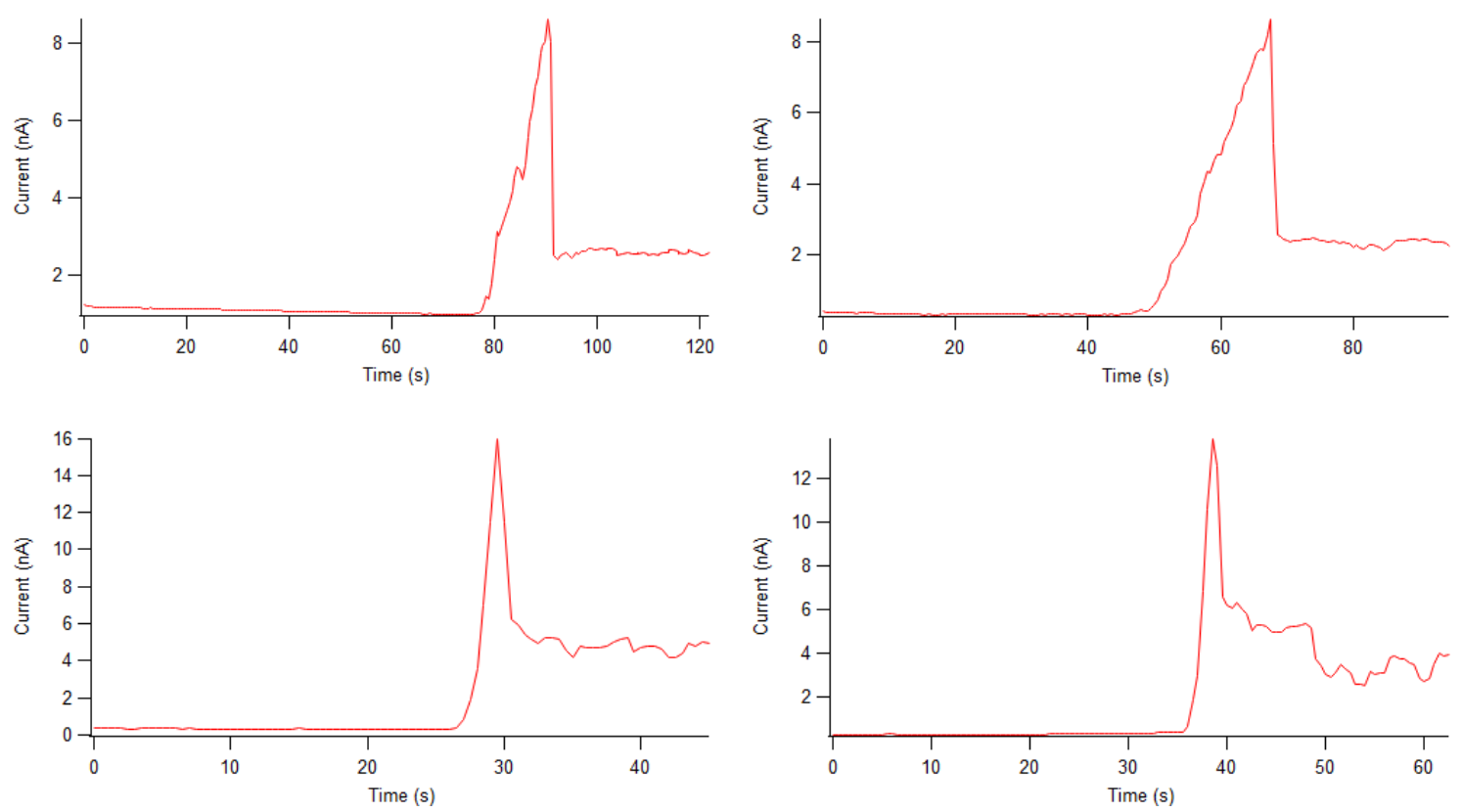

Figure S4. Nanopore fabrication by laser etching. Four separate traces shown in different devices. Etching occurred in $1 \mathrm{M} \mathrm{KCl} \mathrm{pH} 10$ using a UV laser ( $375 \mathrm{~nm}, 10-15 \mathrm{~mW}$ ) and an applied bias of $300 \mathrm{mV}$.

\section{Device noise characterization}

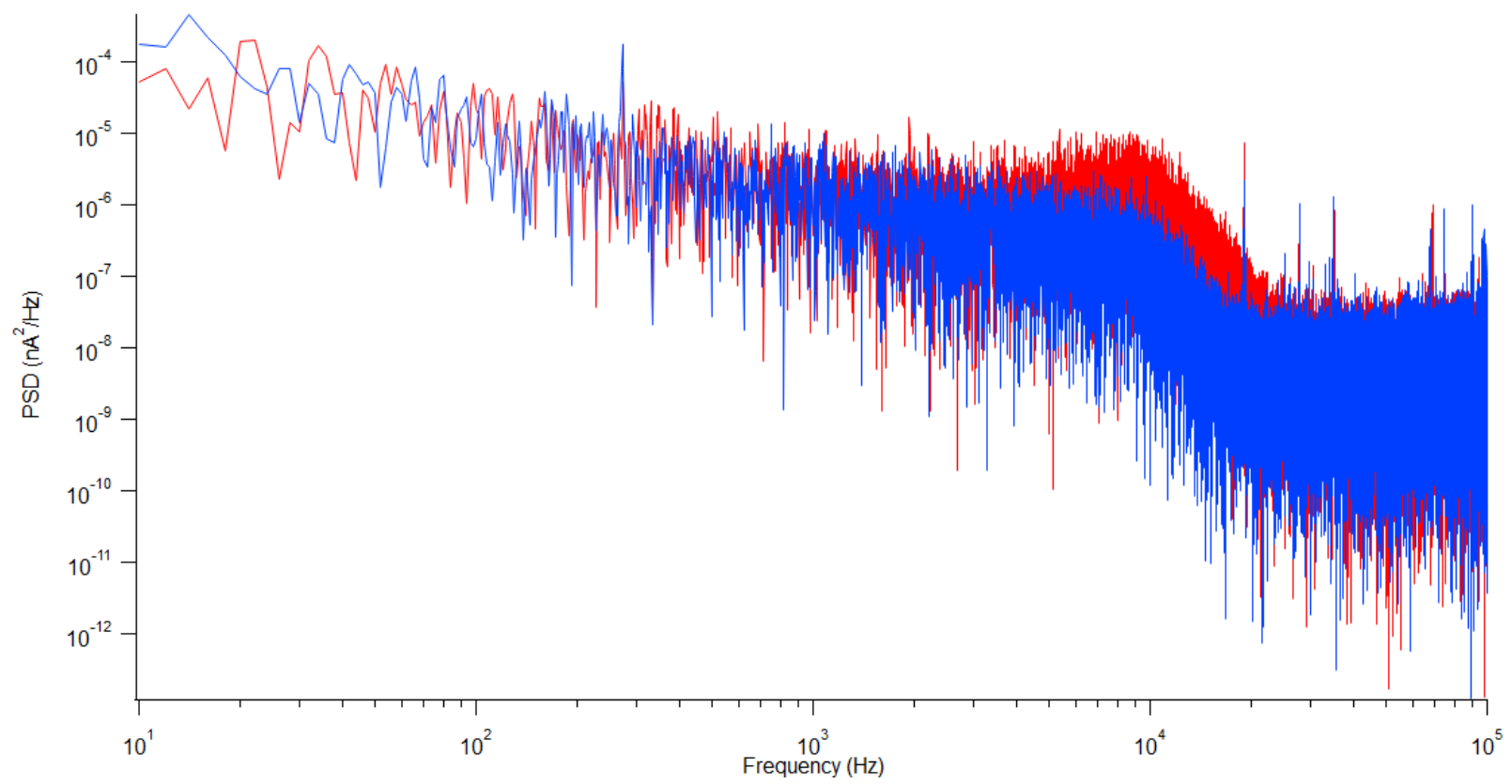

Figure S5. Power spectrum of nanopore in fluidic device. Measurement performed at $300 \mathrm{mV}$ for a 4.5 $\mathrm{nm}$ pore in $1 \mathrm{M} \mathrm{KCl} \mathrm{pH} 7.5$ with/without (red/blue) illumination by a widefield $488 \mathrm{~nm}$ laser $\left(\sim 5 \mathrm{~W} / \mathrm{cm}^{2}\right)$. The signal was acquired at $250 \mathrm{kHz}$ and filtered by an external Bessel filter at $10 \mathrm{kHz}$. 


\section{Genomic DNA extraction protocol}

Samples were prepared according to the IrysPrep Plug Lysis Long DNA Isolation Protocol (Bionano Genomics Inc.) with some modifications similar to Gabrieli et al. ${ }^{2}$ Briefly, $1 \times 10^{6}$ human colon cancer cells were washed twice with PBS, resuspended in cell suspension buffer (CHEF mammalian DNA extraction kit, Bio-Rad), and incubated at $43^{\circ} \mathrm{C}$ for $10 \mathrm{mins} .2 \%$ low melting agarose (CleanCut agarose, Bio-Rad) was melted at $70^{\circ} \mathrm{C}$ and incubated at $43^{\circ} \mathrm{C}$ prior to adding to the resuspended cells at a final concentration of $0.7 \%$. The mixture was then cast into a plug mold and incubated at $4^{\circ} \mathrm{C}$ until solidified. Plugs were incubated twice with $167 \mu$ l proteinase $\mathrm{K}$ (Quiagen) in $2.5 \mathrm{ml}$ lysis buffer (100 mM EDTA, $0.2 \% \mathrm{w} / \mathrm{v}$ sodium deoxycholate, $1 \% \mathrm{w} / \mathrm{v}$ sodium lauryl sarcosine, $\mathrm{pH} 8.0$ ) for $2 \mathrm{~h}$ at $50^{\circ} \mathrm{C}$ followed by an overnight incubation. Plugs were then incubated with $50 \mu \mathrm{l}$ RNase (Qiagen) in $2.5 \mathrm{ml}$ TE (10 mM Tris-HCl, $1 \mathrm{mM}$ EDTA) for $1 \mathrm{~h}$ at $37^{\circ} \mathrm{C}$ on a horizontal shaker. Plugs were washed three times with $10 \mathrm{~mL}$ of wash buffer (10 mM Tris, pH 8, $50 \mathrm{mM}$ EDTA) and manual shaking for $10 \mathrm{~s}$. Plugs were then washed five times by adding $10 \mathrm{ml}$ of wash buffer on a horizontal shaker. Following washes, plugs were stored at $4^{\circ} \mathrm{C}$ in wash buffer. In order to extract the DNA, plugs were washed five times in TE, incubated twice with 2 volumes of $1 \times \beta$-Agarose I buffer on ice for 30 mins, melted for 2 mins at $70^{\circ} \mathrm{C}$ and then incubated with 1 unit of $\beta$-Agarose I for 1 hour. High molecular weight DNA was then purified by drop dialysis using a 0.1 $\mu \mathrm{m}$ dialysis membrane (Millipore) floated on TE. To achieve homogeneity, viscous DNA was incubated at $25^{\circ} \mathrm{C}$ for 48 hours.

\section{Summary of tested devices}

Table S1. Overview of fabrication and experimentation results

\begin{tabular}{|c|c|c|c|c|c|}
\hline & $\begin{array}{c}\text { Membrane Alignment } \\
\text { (Aligned/Misaligned) }\end{array}$ & $\begin{array}{c}\text { Anodic Bonding } \\
\text { (Intact/Collapsed) }\end{array}$ & $\begin{array}{c}\text { Nanopore } \\
\text { Fabrication } \\
\text { (Drilled/Undrilled) }\end{array}$ & $\begin{array}{c}\text { Nanopore } \\
\text { Stability } \\
\text { (Stable/Unstable) }\end{array}$ & $\begin{array}{c}\text { Translocations } \\
\text { (Detected/Not } \\
\text { Detected) }\end{array}$ \\
\hline $\begin{array}{c}\text { Wafer } \\
\text { A }\end{array}$ & $36 / 8$ & $36 / 0$ & $24 / 2$ & $21 / 3$ & - \\
\hline $\begin{array}{c}\text { Wafer } \\
\text { B }\end{array}$ & $16 / 29$ & $16 / 0$ & $13 / 2$ & $11 / 2$ & $5 / 4$ \\
\hline $\begin{array}{c}\text { Wafer } \\
\text { C }\end{array}$ & $39 / 5$ & $1 / 0$ & $2 / 0$ & $1 / 1$ & $1 / 0$ \\
\hline
\end{tabular}

The membrane alignment is affected by the quality of the backside alignment as well as the difference between the expected and actual membrane size after $\mathrm{KOH}$ etching. Anodic bonding yielded fully bonded chips without membrane collapse following significant optimization of the bonding parameters (see main text). In cases where translocations were not electrically/optically detected, occasionally electrical collision events were observed. 


\section{Pillar hooking and unhooking examples}

(a)

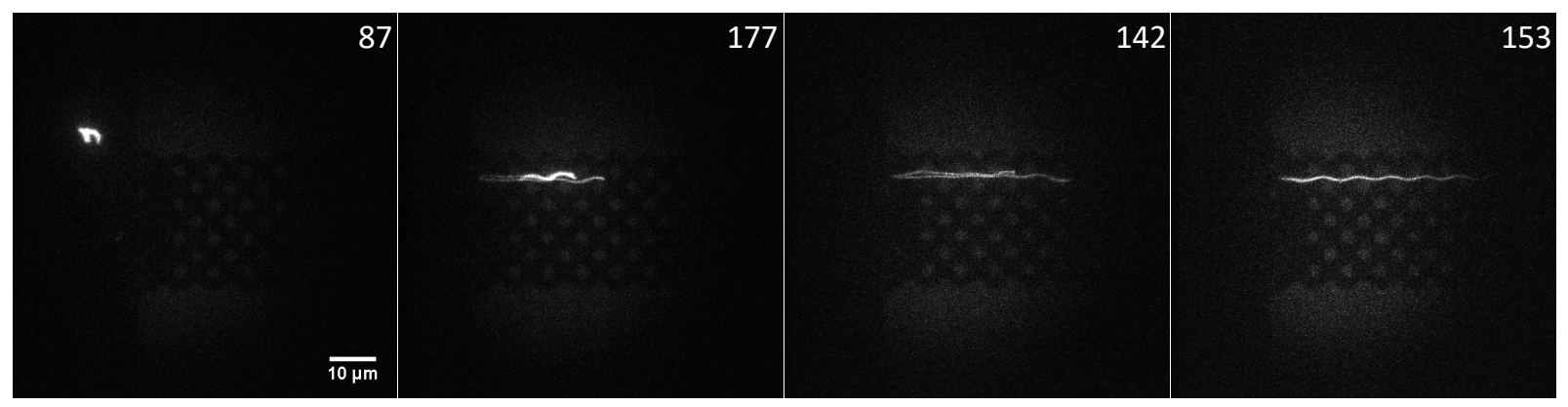

(b)

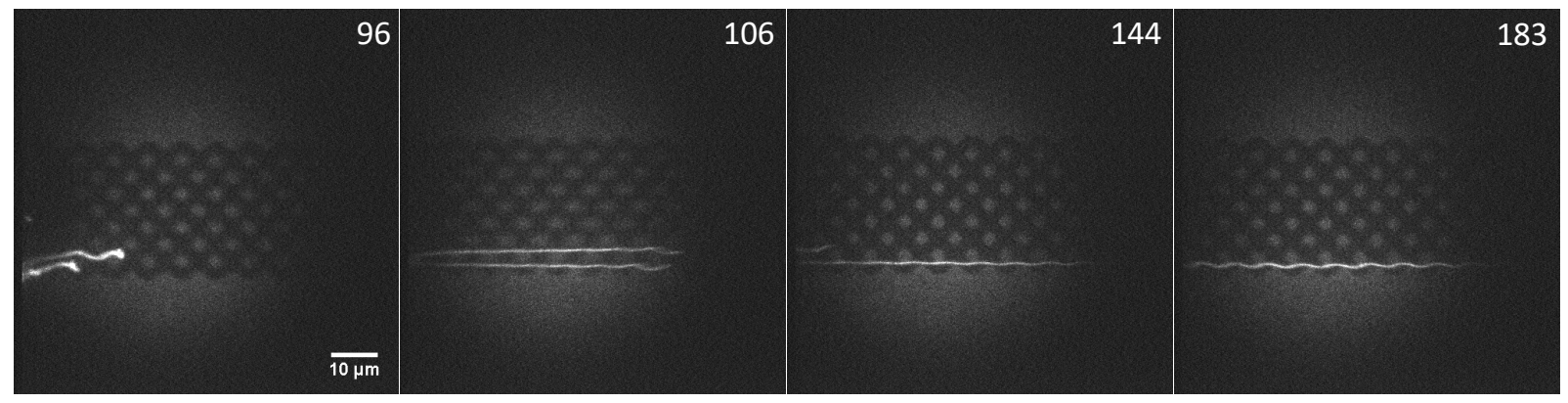

Figure S6. Pillar hooking and unhooking. Additional examples (a) and (b) of YOYO-1 labelled DNA pulled through the pillar array. In both examples, molecules are uncoiled by hooking onto the pillars. Frame numbers are given in the top right (25 ms exposure, 31.07 FPS). Images acquired at 100x.

\section{Polymer extension estimation}

The DNA molecule passes through a pillar array with a non-unity aspect ratio $200 \mathrm{~nm} \times 2 \mu \mathrm{m}$ (height $\mathrm{x}$ width). Taking the geometric average of the channel dimensions, $D_{A v}=\left(D_{1} D_{2}\right)^{0.5} \approx 630 \mathrm{~nm}$, which is significantly greater than the polymer's persistence length, we can place the stretched polymer in the de Gennes regime, accounting for only partial extension. ${ }^{3}$ Hence, most of the stretching is due to hydrodynamic induced tension during a transient period (hook transition). The average steady-state extension in a population of polymers is a function of the fluid strain rate and the polymer relaxation time. We can use the Deborah number, $D e$, defined as the strain rate parallel to flow $\left(\dot{E}=\frac{\partial v}{\partial x}\right)$ multiplied by the longest polymer relaxation time $\left(t_{\text {relax }}\right)$ to predict the fractional extension. The strain rate can be determined experimentally and is extracted from the experiment of Figure 3, $\dot{E} \sim \frac{145 \mu \mathrm{m} / \mathrm{s}}{126 \mu \mathrm{m}} \sim 1.1 \mathrm{~s}^{-1}$. The polymer relaxation time in the de Gennes regime is:

$$
\tau \cong \frac{n_{S}}{k_{B} T} \frac{(P \omega)^{\frac{2}{3}}}{D^{\frac{1}{3}}} L^{2},
$$

where $n_{s}$ is the solvent viscosity (water, $8.90 \times 10^{-4} \mathrm{~Pa} \cdot \mathrm{s}$ ), $\mathrm{k}_{\mathrm{B}}$ is the Boltzmann constant, $\mathrm{T}$ is the temperature $(298 \mathrm{~K}), \mathrm{P}$ is the persistence length $(50 \mathrm{~nm}), \omega$ is the polymer's effective width $(\omega \approx 7.8 \mathrm{~nm}$ for $I \approx 50 \mathrm{mM})$, $\mathrm{D}$ is the channel diameter $(630 \mathrm{~nm})$, and $\mathrm{L}$ is the contour length $(e . g .60 \mu \mathrm{m})$. Plugging in 
these values yields $\tau \sim 5$. Therefore, De 5, which is above the critical value (0.4) to achieve stretching. For this Deborah number, and given that the molecule relaxes when the pressure is turned off when it reaches the pillar exit, we can expect up to around $85 \%$ stretching, as compared with several reported literature values. Stretching DNA to $85 \%$ requires only about $1 \mathrm{pN}$, relatively easy to achieve, whereas stretching above $85 \%$ requires significantly greater tension (i.e. increasing tension from 5 to $60 \mathrm{pN}$ results in less than $10 \%$ more stretching). ${ }^{4,5,6}$

10. Translocation speed calculation

a)
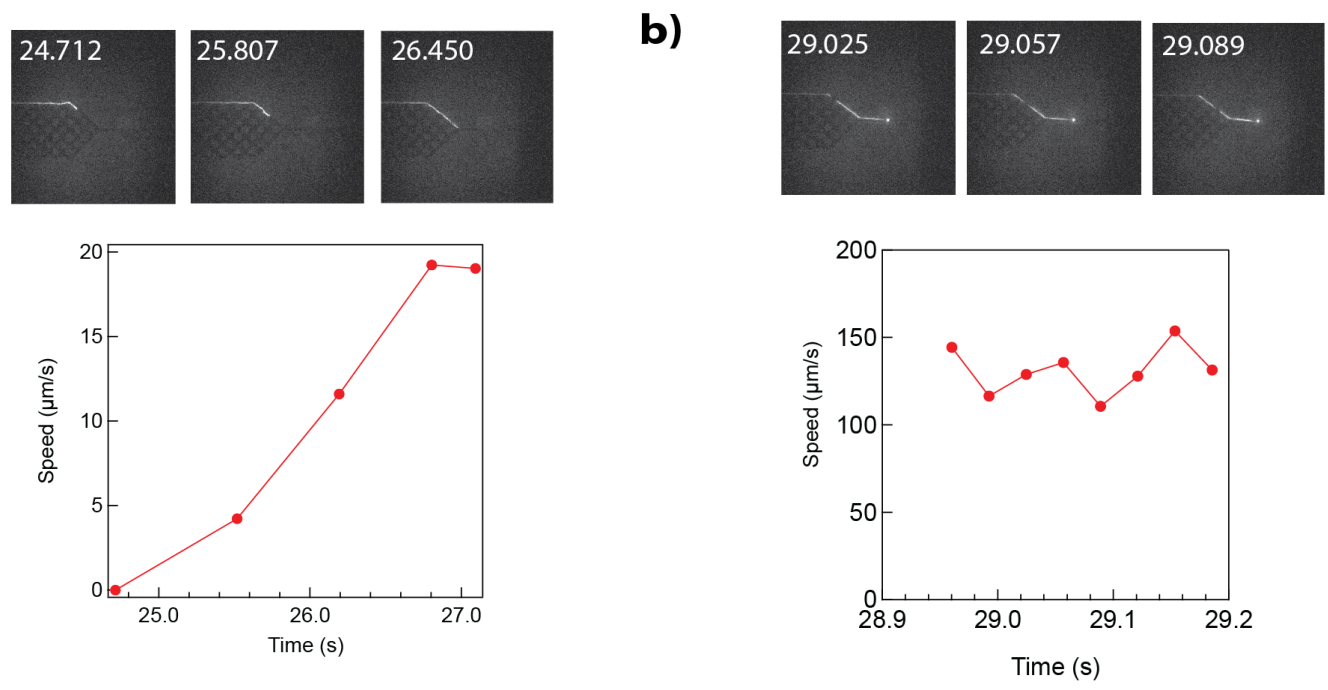

c)
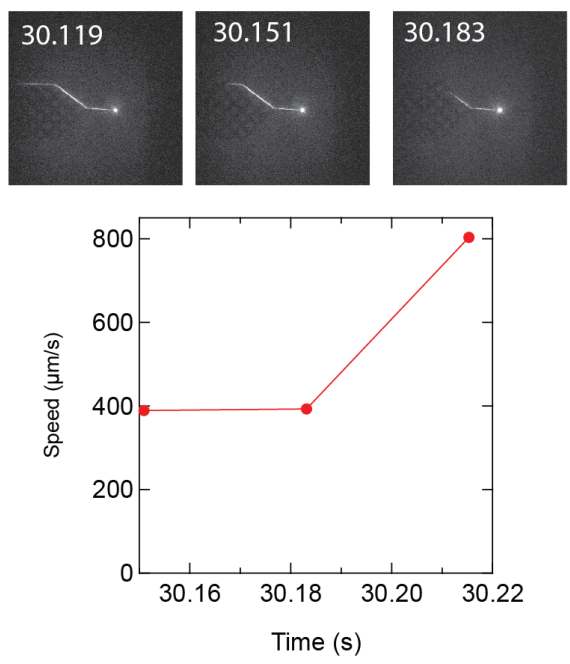

Figure S7. DNA molecule speed before, during, and at the end of translocation. (a) DNA speed during electrophoretic migration to the pore. The initial speed when the vacuum is turned off is zero. (b) Translocation speed measured using dark contrasted band as reference. The band is likely an AT-rich region. The translocation speed is roughly constant over 8 frames. (c) Translocation speed measured at end of translocation. The polymer accelerates in the last frame. 


\section{Nanopore collisions}
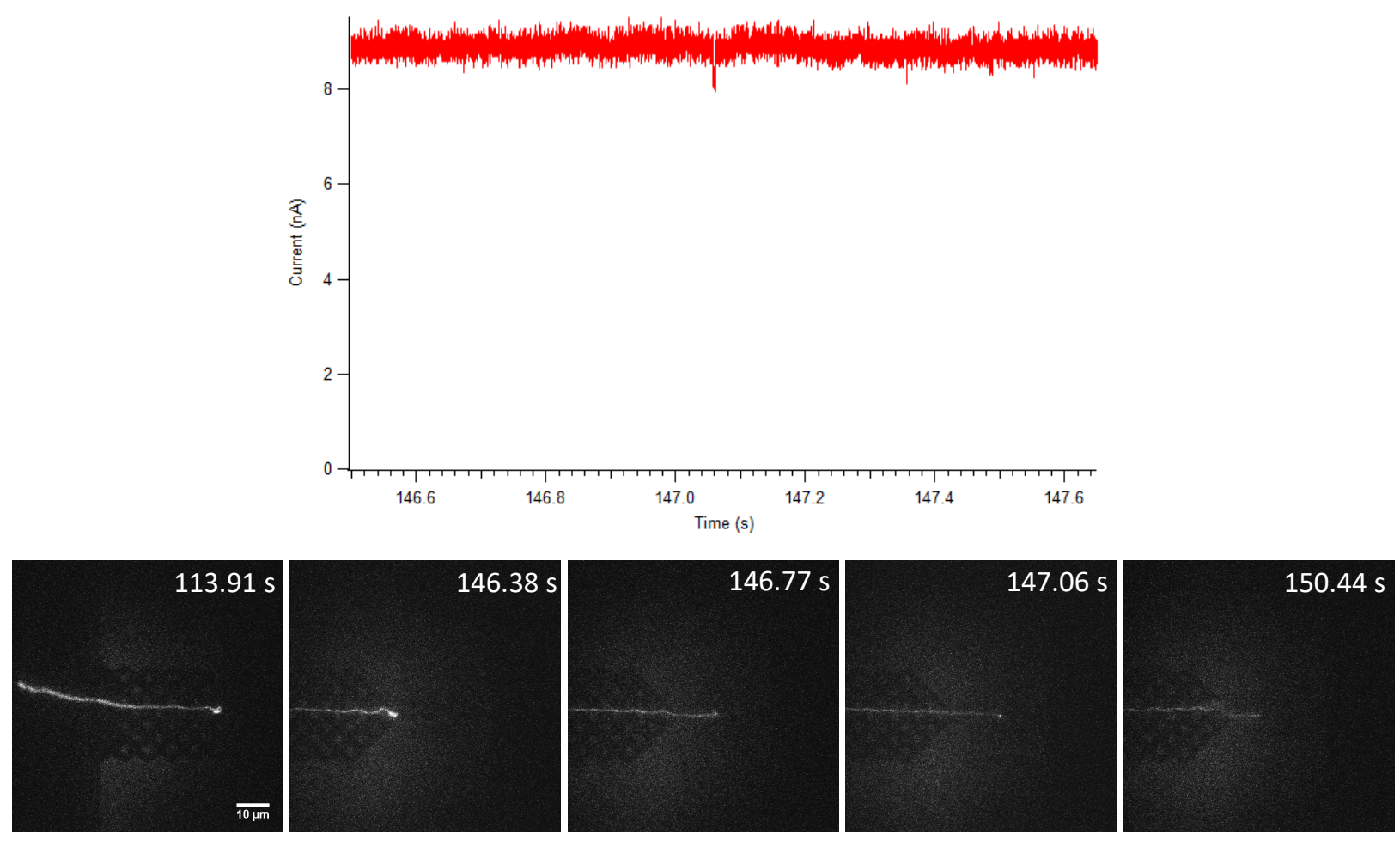

Figure S8. Example collision event. Collision (failed entry) occurs in the frame of $147.06 \mathrm{~s}$, which is exposed for $25 \mathrm{~ms}$. The nanopore diameter is $\sim 6 \mathrm{~nm}$. The DNA molecule is subsequently reversed and removed by vacuum (150.44 s).

\section{References:}

(1) Sidorova, J. M.; Li, N.; Schwartz, D. C.; Folch, A.; Monnat, R. J. Microfluidic-Assisted Analysis of Replicating DNA Molecules. Nat. Protoc. 2009, 4, 849-861.

(2) Gabrieli, T.; Sharim, H.; Nifker, G.; Jeffet, J.; Shahal, T.; Arielly, R.; Levi-Sakin, M.; Hoch, L.; Arbib, N.; Michaeli, Y.; Ebenstein, Y. Epigenetic Optical Mapping of 5-Hydroxymethylcytosine in Nanochannel Arrays. ACS Nano 2018, 12, 7148-7158.

(3) Reisner, W.; Pedersen, J. N.; Austin, R. H. DNA Confinement in Nanochannels: Physics and Biological Applications. Rep. Prog. Phys. 2012, 75, 106601.

(4) Larson, J. W.; Yantz, G. R.; Zhong, Q.; Charnas, R.; D’Antoni, C. M.; Gallo, M. V.; Gillis, K. A.; Neely, L. A.; Phillips, K. M.; Wong, G. G.; Gullans, S. R.; Gilmanshin, R. Single DNA Molecule Stretching in Sudden Mixed Shear and Elongational Microflows. Lab Chip 2006, 6, 1187-1199.

(5) Liu, Y.; Steinberg, V. Single Polymer Dynamics in a Random Flow. Macromol. Symp. 2014, 337, 34-43.

(6) Hsieh, S.-S.; Liou, J.-H. DNA Molecule Dynamics in Converging-Diverging Microchannels. Biotechnol. Appl. Biochem. 2009, 52, 29. 